\title{
Ictericia obstructiva secundaria a tumor de células granulares de la vía biliar extrahepática*
}

\author{
Drs. FRANCO INNOCENTI C. ${ }^{1,2}$, RODRIGO KLAASSEN P., ${ }^{2,3}$, \\ FREDDY BRAVO C. ${ }^{1,2}$, ERNESTO HINRICHS O. ${ }^{1,2}$, FELIPE MARTIN Q. ${ }^{2}$, \\ VANESSA KLAASSEN H., ${ }^{2,3}$, CRISTIAN LEDERMANN S. ${ }^{1,2}$ \\ 1 Departamento de Cirugía, Universidad de Concepción. \\ 2 Servicio Cirugía, Pabellón y Anestesia, Clínica Sanatorio Alemán de Concepción. \\ 3 Departamento de Anatomía Patológica, Universidad de Concepción. \\ Concepción, Chile.
}

\begin{abstract}
Obstuctive jaundice secondary to extrahepatic bile ducts granular cell tumor

Bile ducts granular cell tumor is a rare entity. Of neural origin, mostly benign, may, however, present mimicking malignancy. We report a 32 years old female presenting with painless jaundice and extrahepatic bile ducts stenosis confirmed with MRC. Extrahepatic bile ducts resection is performed. Reconstruction involves four independent ducts to a Roux en Y enteric loop. She has a good postoperative outcome, with no evidence of complications nor recurrence at 17 months of follow up.
\end{abstract}

Key words: Bile ducts granular cell tumor, bile duct, jaundice.

\section{Resumen}

El tumor de células granulares en la vía biliar es una neoplasia rara de origen neural, en su mayoría benigna y cuya presentación puede sugerir patología maligna. Objetivo: Se presenta el caso clínico, características anatomopatológicas, manejo y evolución de una paciente joven que se presenta con ictericia obstructiva por estenosis subcarinal biliar. Paciente y Método: Paciente 32 años, sexo femenino, con ictericia, coluria y prurito. Diagnóstico de estenosis biliar y dilatación de vía biliar intrahepática se confirma con colangiorresonancia magnética. Se realiza resección de vía biliar extrahepática desde supracarinal que incluye vía biliar distal. Reconstitución bilioentérica a Y de Roux que involucra cuatro conductos intrahepáticos. Evoluciona en forma satisfactoria en el postoperatorio. El seguimiento alejado a 17 meses revela una satisfactoria condición de la paciente, sin signos de complicación o recidiva. Conclusión: El manejo por un equipo de experiencia multidisciplinario nos permitió ayudar a una paciente con rara patología, benigna en lo histológico, pero que puede representar un gran desafío técnico.

Palabras clave: Tumor de células granulares, vía biliar, ictericia.

*Recibido el 27 de noviembre de 2010 y aceptado para publicación el 14 de marzo de 2011.

Correspondencia: Dr. Franco Innocenti C.

Pedro de Valdivia 801, Concepción, Chile.

f.innocenti@vtr.net 


\section{Introducción}

El tumor de células granulares es una neoplasia cuyo origen citogenético se relaciona con las células de Schwann ${ }^{1}$, aunque se ha postulado que se originaría a partir de una célula precursora con capacidad de diferenciarse a células de Schwann o a células granulares ${ }^{2}$. Su naturaleza es benigna y constituye sólo el 1,1\% de los tumores benignos de la vesícula biliar $^{3}$. Aparece con mayor frecuencia en mujeres entre la cuarta y sexta décadas de la vida, aunque puede ocurrir a cualquier edad. La presentación biliar del caso que nos ocupa es rara ${ }^{4-6}$.

\section{Caso clínico}

Paciente de 32 años de edad, de sexo femenino, que consulta por prurito de tres meses de evolución, agregándose coluria e ictericia dos semanas antes de la evaluación médica. No presenta antecedentes remotos mórbidos significativos. Durante su estudio, la ultrasonografía abdominal revela dilatación de la vía biliar intrahepática, con bilirrubinemia mayor a $15 \mathrm{mg} \%$, a expensas de la directa, y elevación de enzimas canaliculares. Ca-19-9 normal. Colangiorresonancia magnética preoperatoria confirma significativa dilatación de la vía biliar intrahepática supracarinal y estenosis severa de ambos conductos hepáticos a ese nivel (Figura 1). Se plantea diagnóstico de neoplasia o de estenosis benigna.

Se realiza resección de la vía biliar extrahepática más linfadenectomía. La biopsia rápida informada por el patólogo sugiere inmediatamente tumor de células granulares.

Se reconstituye mediante colangioenteroanastomosis triple a asa yeyunal en Y de Roux, realizando plastía en dos de los cuatro conductos para disminuir el número de anastomosis a tres. Se deja dos catéteres transentéricos de alimentación pediátrica número 3 a conductos biliares para acceso colangiográfico. Colangiografía de control postoperatoria ambulatoria a los 21 días, no muestra evidencia de fuga ni estenosis, con buen vaciamiento a distal (Figura 2). La paciente evoluciona satisfactoriamente en el postoperatorio. A los 17 meses, se encuentra en buenas condiciones sin signos de recidiva.

\section{Macroscopía}

Según informe de anatomía patológica, se recibe para biopsia, además de tejido linfonodal de grupos 12 y 13, una pieza de vía biliar extrahepática compuesta por colédoco, cístico, conducto hepático izquierdo, conductos segmentarios VI más VII común, V y VIII. En la zona de confluencia de los cuatro últimos existe un área de engrosamiento de la pared de hasta $8 \mathrm{~mm}$ con estenosis marcada del lumen.

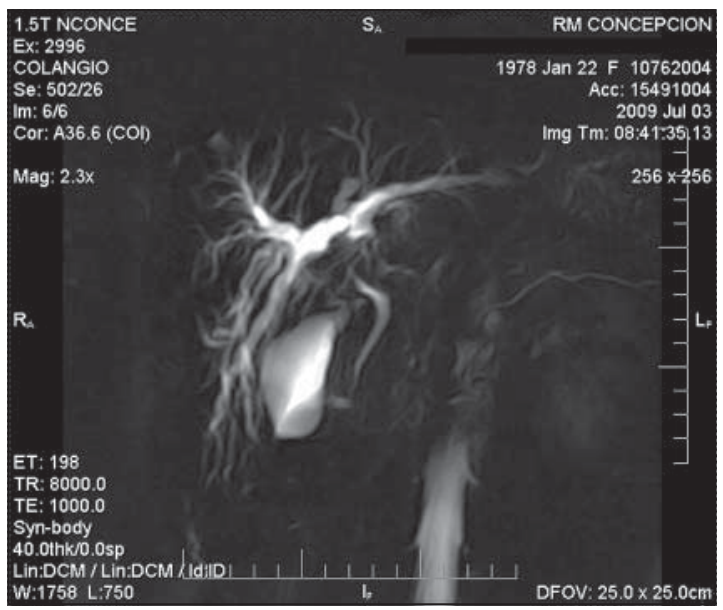

Figura 1. Colangiografía Preoperatoria: Se observa significativa dilatación de la vía biliar supracarinal con amputación segmentaria de aproximadamente $3 \mathrm{~cm}$ a distal, desde donde vía biliar es normal hacia duodeno.

\section{Microscopía}

En la zona de pared engrosada descrita se observa una neoplasia de células redondas y ovaladas grandes, con núcleos hipercromáticos y abundante citoplasma eosinófilo granular (Figura 3). Estas células infiltran la pared de los conductos biliares formando láminas, cordones y nódulos entre los conductillos y glándulas biliares normales. No hay atipía, pleomorfismo celular ni mitosis. El estudio complementario con inmunohistoquímica (anticuerpos monoclonales) es positivo para proteína S-100 (Figura 3), Enolasa Neurono Específica (NSE, Figura 4), CD68 (Cluster of Differentiation 68) y Vimentina.

Por otra parte, Desmina y Actina (marcadores musculares) son negativas.

\section{Discusión}

El tumor de células granulares es una neoplasia benigna descrita en numerosos tejidos y órganos. Es muy rara en el tracto biliar, en donde la sintomatología puede sugerir un proceso maligno ${ }^{7}$. El tamaño varía entre 1 a $2 \mathrm{~cm}$ de diámetro. Se presenta como uno o múltiples nódulos blandos, ovalados, de bordes bien o mal delimitados, a la sección es de color amarillento.

Histológicamente está formado por células de forma poligonal, con bordes mal definidos, citoplasma eosinófilo abundante y típicamente granular; los núcleos son pequeños con cromatina densa. Los gránulos citoplasmáticos corresponden a estructuras similares a lisosomas que contienen mielina o sus 


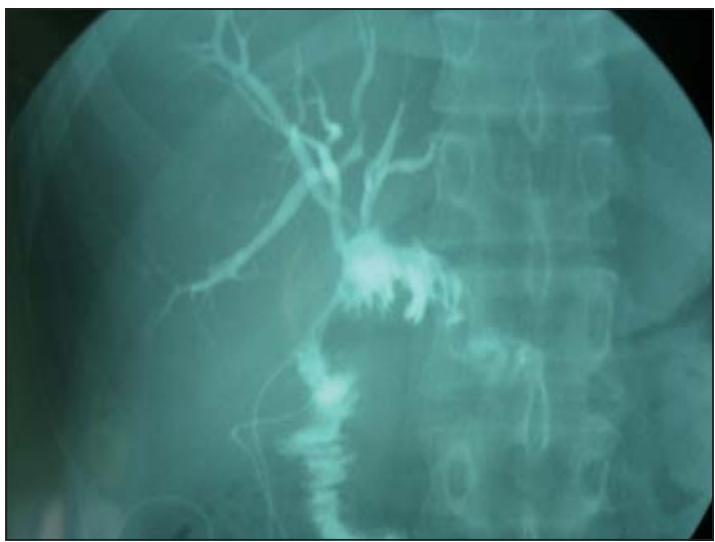

Figura 2. Colangiografía postoperatoria: Se observa la triple anastomosis colangioyeyunal a cuatro conductos (dos con plastía para una anastomosis) sin evidencia de fuga, con buen vaciamiento a distal.

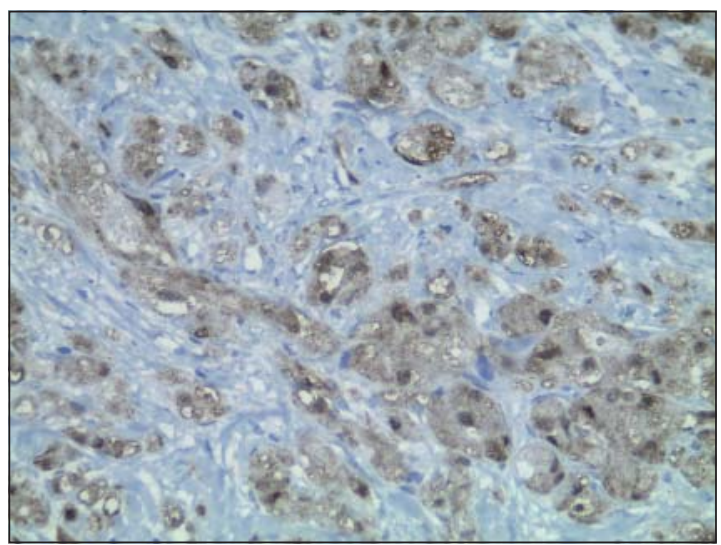

Figura 4. Proteína S100 positiva en el citoplasma de células tumorales. 200x.

productos metabólicos, sugiriendo un origen neural ${ }^{8}$. Atipía y mitosis son raras. Histoquímicamente son positivos para proteína S-100, Enolasa Neurono Específica (NSE) (7) y CD68. Son negativos para marcadores musculares y epiteliales. Hay aproximadamente 56 casos benignos publicados de tumor de células granulares en el tracto biliar ${ }^{9,10}$.

Este caso nos permite recordar su rareza. El tratamiento de elección es resección quirúrgica con reconstitución de la vía biliar.

Los casos malignos son aún más raros; las características de malignidad son necrosis, células fusadas, núcleo vesicular con nucléolo prominente, más de 2 mitosis por 10 campos mayores, pleomorfismo y alta relación núcleo-citoplasmática. Afortunadamente, ninguna de estas características se observó en el caso de esta joven paciente.

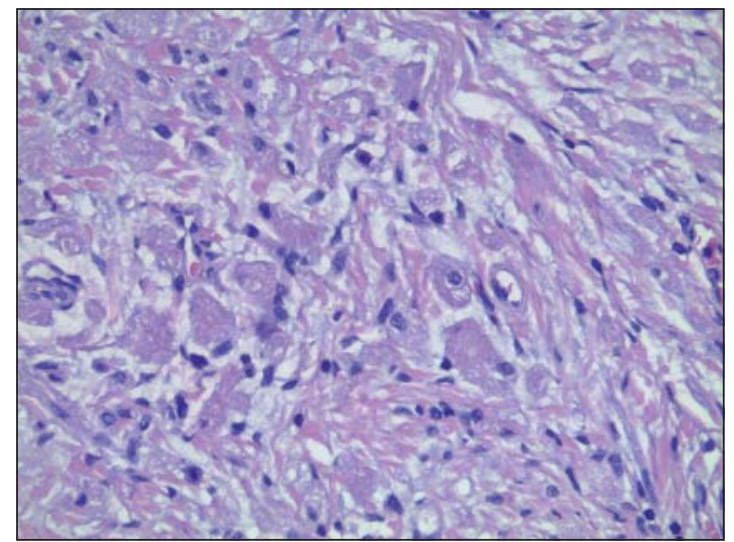

Figura 3. Células tumorales con citoplasma granular. H\&E 200x.

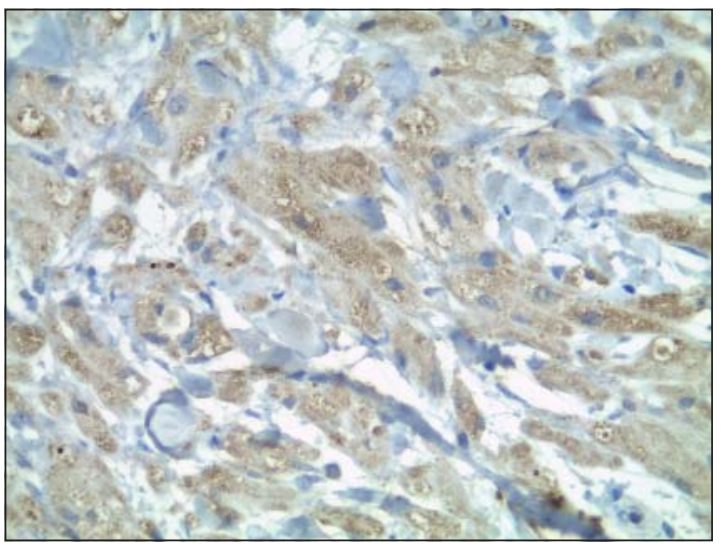

Figura 5. NSE positiva en el citoplasma de células tumorales. 400x.

\section{Referencias}

1. Cheslyn-Curtis S, Russell RCG, Rode J, Dhillon AP. Granular cell tumor of the common bile duct. Postgraduate Medical Journal 1986;62:961-3.

2. Rode J, Dhillon AP, Papadaki L. Immunohistochemical staining of granular cell tumour for neurone specific enolase: Evidence in support of a neural origin. Diagnostic Histopathology 1982;5:205.

3. Christensen A, Ishak K. Benign tumors and pseudotumors of the gallbladder. Archives of Pathology 1970;90:423-9.

4. Lack EE, Worsham GF, Callihan MD, Crawford BE, Klappenbach S, Rowden G, et al. Granular cell tumour: A clinicopathological study of 110 patients. Journal of Surgical Oncology 1980;13:301.

5. Eisen RN, Kirby WM, O’Quin JL. Granular cell tumor 
of the biliary tree. A report of two cases and a review of the literature. Am J Surg Pathol. 1991;15:460-5.

6. Butler JD, Brown KM. Granular cell tumor of the extrahepatic biliary tract. Am Surg. 1998;64;1033-6.

7. Chandrasoma P, Fitzgibbons P. Granular cell tumor of the intrapancreatic common bile duct. Cancer 1984;53:2178-82.

8. Lochan R, Balupuri S, Bennett MK, Manas DM. Granular cell tumor as an unusual cause of obstruction at the hepatic hilum: Report of a case. Surg Today
2006;36:934-6.

9. Boekhorst DS, Gerhards MF, van Gulik TM, Gouma DJ. Granular cell tumor at the hepatic duct confluence mimicking Klatskin tumor: a report of two cases and a review of the literature. Dig Surg. 2000;17:299303.

10. Heuer T, Lahrtz HJ, Gerards H, Berkovic D, Kania U, Reis HE. Posthepatic icterus caused by a solitary granular cell tumor of the common bile duct. Z Gastroenterol. 2004;42:323-5. 